\title{
A Proposed Holistic Approach to Fire Safety Management in Zambian Markets
}

\author{
Kaiko Mubita $^{{ }^{*}}$, Inonge Milupi ${ }^{2}$, Pauline Namakau Monde ${ }^{3}$, Steriah, M Simooya ${ }^{4}$ \\ ${ }^{1,2}$ The University of Zambia, School of Education \\ ${ }^{3,4}$ Department of Language and Social Sciences Education, Lusaka, Zambia
}

*Corresponding Author: Kaiko Mubita, The University of Zambia, School of Education

\begin{abstract}
This article reviews literature on fire safety in market places and proposes a holistic approach to fire safety and security in Zambian markets. This is because of many reported incidents of fire in some markets in Zambia. Based on the view that market environments in Zambia consist of physical, social, economic and political dimensions, we argue that management of fire in these market places is a critical factor that needs a concerted effort from many stakeholders. To this effect, ensuring fire safety management in market places in Zambia requires a holistic approach that encompasses a thorough grounding in knowledge about different dimensions of the market environments and the basics of fire safety. Based on these arguments, we argue that market fire facilities maintenance, surveillance of market environment, education and training of marketers and consumers, quality of market structures and monitoring and evaluation are critical aspects of a holistic approach to fire safety management in Zambian markets. Bearing this in mind, this paper, therefore, presents an approach that can be helpful in making Zambian markets safe from fires.
\end{abstract}

Key terms: Fire safety, holistic approach, fire management, market, Zambia

\section{INTRODUCTION}

A market is a commercial place where buying and selling takes place. According to Kenton (2020) a market is a place where two parties can gather to facilitate the exchange of goods and services. The parties involved are usually buyers and sellers. The market may be physical like a retail outlet, where people meet face-to-face, or virtual like an online market, where there is no direct physical contact between buyers and sellers. While parties may exchange goods and services by barter, most markets rely on sellers offering their goods or services in exchange for money from buyers. It can be said that a market is the process by which the prices of goods and services are established. Markets facilitate trade and enable the distribution and resource allocation in a society.

Market places are found all over the world for the sole purpose of buying and selling of goods and services. According to Tabassum et al. (2014), currently there is a fast growth of markets or shopping centres in most urban centres of developing countries. This increased development and interaction increase the level of exposure to certain hazards and disasters.

Some markets both in and outside Zambia have recorded significant losses from natural and human induced hazards and disasters. These disasters include fires, landslides, strong winds, floods and many others. These disasters tend to disrupt normal market operations and therefore affect economies at household level, locally and internationally. Fire hazards and disasters in markets is what this paper focused on. According to World Health Organisation (2004) fires cause over 300,000 deaths annually and are the fourth largest cause of accidental injury globally (after road accidents, falls, and drowning). Over 95\% of the deaths and burn injuries are in Low and Middle-Income Countries (LMICs), where death rates are nearly six times higher than in high-income countries (World Health Organisation, 2004).

In the recent past and beyond, markets in different parts of Africa have suffered from fire outbreaks destroying property worthy of millions of dollars. For example, in Nigeria, Premium Times reported a fire incidence as follows:

'About 14 shops and 16 kiosks have been burnt in a fire outbreak in the early hours of Sunday at Adeniji Adele Market, Lagos. This was contained in a 
statement released by the Lagos State Emergency Management Agency (LASEMA).' (Premium Times, 23 August 2020)

In Nigeria also, another fire incident was reported as follows:

Nigerian fire fighters were trying to extinguish a major fire at the Balogun market in central Lagos on Tuesday. Thick black smoke and flames were shooting up from five-storey buildings surrounding the market as fire trucks attempt to get access to the fire. Residents were throwing what belongings they could from the buildings, and some people on the rooftops were using small buckets of water (The Associated Press, November 5, 2019)

In Zimbabwe, a fire incident was reported Mbare in 2019 as follows:

A gas tank used by an informal trader for television and radio repairs reportedly exploded on Tuesday morning, leading to fire that destroyed a complex at Mbare Musika, with property worth thousands of dollars going up in smoke. The incident occurred a few days after a part of Siyaso Informal Traders market in Magaba was ravaged by fire. The Mbare Musika inferno is reported to have started at around lam, with Harare's fire brigade team arriving at the scene when nearly all property in the complex was already burnt.

(The Herald, 31 July, 2019)

In Malawi, an incident of market fire was reported in Lilongwe as follows:

Property estimated at K1.26 billion was lost in the fires which gutted the Mzuzu Central and Lilongwe Tsoka Markets this year, the Minister of Local Government and Rural Development disclosed Friday. Trasizio Gowelo, who chairs a Ministerial Committee looking into the fires that gutted the two markets, made the revelation at a press briefing he jointly held with Minister of Home Affairs and Internal Security Paul Chibingu in Lilongwe...

(Malawi News Agency, September 21, 2014)

All the foregoing reports about market fires in selected countries show that market places were not entirely safe in terms of fire hazards and disasters.

Zambia has not been an exception to fire incidents in markets. In Zambia, incidences of fire outbreaks in markets have caused social and economic losses to people. This has set back the progress of persons, institutions and infrastructures in numerous dimensions. These market fires could render some people jobless, damage the environment, disrupt economic activities and worsening the problem of poverty. These fire incidences and accidents generate much discussion based on causation rumours relating to sabotage, misfortune, arson, electrical faults and many more.

The Zambian media has been reporting stories of markets on fire for some time now. Table 1 presents selected media reports of fire incidents in selected markets in Zambia.

Table1. Selected media reports on market fires in Zambia

\begin{tabular}{|c|c|c|}
\hline Serial No. & Media & Story \\
\hline 1. & The Zambian Observer (April 16, 2017) & Kamwala market in Lusaka on fire just now \\
\hline 2. & Zambia Reports (May 20, 2017) & Senanga Market on fire \\
\hline 3. & Lusaka Times,(January 30, 2009) & Fire destroys goods at Chisokone Market \\
\hline 4. & Zambia Reports (August 30, 2017) & Zambia's Masala market on fire \\
\hline 5. & Lusaka Times (July 4, 2017) & Lusaka City Market is on Fire \\
\hline
\end{tabular}

As noted by the media reports in table 1, it is clear that market places in Zambia have had challenges related to fire safety management. Against this background, this article reviews literature on fire safety in market places generally and proposes a holistic approach to fire safety and security in Zambian markets.

\section{LITERATURE REVIEW}

\subsection{Introduction: What is Fire?}

According to National Wildfire Coordinating Group (2008) fire is the rapid oxidation of a material in the exothermic chemical process of combustion, releasing heat, light, and various reaction products. 
Fire is a form of a chemical reaction that involves the rapid oxidation of combustible fuel (material) with the subsequent liberation of heat and light. Elabbani (2015) defines fire, or combustion, as a chemical reaction in which a substance combines with oxygen and heat is released.

\subsection{Fire Chemistry}

Before looking at fire safety in markets, there is need to build knowledge of fire chemistry and understand exactly what causes fire. First and foremost, there is need to understand the fire triangle and its elements. The Fire Triangle is a simple way of understanding the components of fire. Each side of the triangle represents one of three elements needed to have a fire. These elements are oxygen, fuel and heat (See figure 1). Fire is a chemical reaction. Therefore, without one of these elements, fire cannot start or be sustained. The air that surrounds us contains approximately $21 \%$ oxygen. Air supporting a fire must be at least $16 \%$ oxygen content to burn. In large fires where fire-fighters are called in, decreasing the amount of oxygen is not usually an option because there is no effective way to make that happen in an extended area. Fuel is considered any material capable of burning and is characterized by its moisture content (how wet the fuel is), size, shape, quantity, and the arrangement in which it is spread over the landscape. Fuel sources includes any kind of combustible materials like grass, wood, paper, shrubs, trees, houses, and so on. A heat source is responsible for the initial ignition of fire, and heat is also needed to maintain the fire and permit it to spread. Heat allows fire to spread by removing the moisture from nearby fuel, warming surrounding air and preheating the fuel in its path. Heat sources include lightning, cigarettes, power lines, engine sparks, matches, magnifying glass and many more. A fire occurs when all three of these components react together in time and space. A fire can be put out, prevented or the impacts reduced by removing, reducing or separating these elements. Reducing unwanted ignition sources by humans helps to decrease the probability of a fire occurring in any place (Daniel E. Della-Giustina, 2014; Furness and Muckett, 2007; Elabbani, 2015).

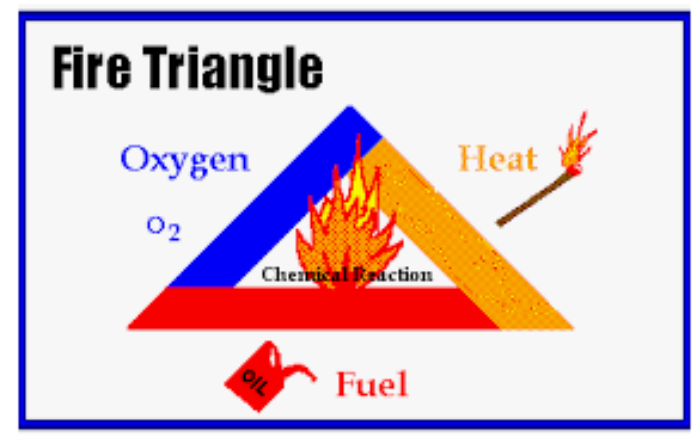

Figure1. Fire triangle

\subsection{Uses and Dangers of Fire}

The positive effects of fire include stimulating growth and maintaining various ecological systems. Its negative effects include hazard to life and property, atmospheric pollution, and water contamination. Fire can affect ecological systems. If fire removes protective vegetation, heavy rainfall may lead to an increase in soil erosion by water (Morris and Moses, 1987). Fire has been used by humans in rituals, in agriculture for clearing land, for cooking, generating heat and light, for signalling, propulsion purposes, smelting, forging, incineration of waste, cremation and as a weapon or mode of destruction.

\subsection{Nature of Market Environments and Infrastructure in Zambia}

Type of market environments and infrastructure are a factor in fire causation in Zambia. The type or quality of infrastructure and environments in Zambian markets are described as follows:

- Types of Buildings: Most shops and stands in markets are built of wood, papers and metal sheets. In some cases, especially in rural areas, even grass is used to build shops and stands. These materials are flammables and any slight start of fire could result in a disaster. Ozioma (2020) also noted that in Nigeria, most of the shops that were razed to the ground were shanty houses made with woods and metal sheets. Most of the stands and shops, especially in rural markets were of substandard. They were vulnerable to fire, strong winds and heavy rains. Ayobami et al. (2016) also noted that most of the fire outbreaks at markets in Lagos State Nigeria have been attributed to vulnerable building materials. 
- Market environment: Most markets in Zambia, especially in urban areas are densely populated. The market stands are very close to each other (in most cases attached). Because market infrastructure is close to each other (stands, shops, restaurants, kiosks, etc). A fire could easily sweep across all infrastructure within a short time and destroy property worthy of millions. Addai et. al. (2016) in his study on 'Trends of fire outbreak in Ghana and ways to prevent these incidents' noted that as markets do not have proper layouts, accessibility by fire tenders is always difficult when there is a fire outbreak because every major market in Ghana faces the problem of congestion. This congestion could make it difficult to identify intruders who could be potential arsonists.

\subsection{Causes of Fire in Markets}

There are several and varied causes of fires in market environments. Different researches have brought forth some of these causes as follows:

In his study on 'assessment of the awareness of fire insurance in the informal sector: a case study of Kumasi central market in Ghana,'Twum-Barima (2014), noted that power fluctuations accounted for $26 \%$ of the total fire incidents in markets. He further underscored the following causes (with percentage): cooking with naked fire in the market, 19\%; overloading of electrical appliances, $16 \%$; improper and old electrical wiring system, $13 \%$; illegal tapping of electrical power from the national grid, 11\%; use of substandard electrical materials, $8 \%$; and use of defective generators, $7 \%$ (TwumBarima, 2014). The fore going is observed in Zambian markets too. Marketeers tend to cook their food within market premises. More so, there are small restaurants that even cook on braziers. All these could be sources of fire in Zambian markets. Moreover, improper electrical wiring system could be a cause of fires in markets as certain media houses in Zambia reported in the following example:

\section{Popular super market Melissa in Kabulonga has reportedly been gutted by fire in the early hours of today. The cause of the fire has yet to be established but early indications point to an electrical fault (Zambia Reports, December 9, 2016)}

Twum-Barima (2014) also noted the extent of severity in cases of fire due to congested situations in markets in Ghana. According to Twun, markets in Ghana do not have proper layouts; accessibility by fire tenders is always difficult when there is a fire outbreak because every major market in Ghana faces the problem of congestion (Addai et. al, 2016). For this reason, fire hydrants have been obscured by stalls, and lanes that fire trucks need to use to access the markets are converted into stalls, etc. All of these factors come together to cause the kind of destruction that occurs during such outbreaks of fire. The typical result of these outbreaks is the destruction of goods and structures whose costs run into thousands of Ghanaian Cedi (Addai et,al, 2016).

Ozioma (2020) also presented the following as reasons why the fire started and spread faster in Nigerian open markets:

- Types of Buildings: According to Ozioma (2020) most of the shops that are razed to the ground are shanty houses made with woods and metal sheets. These were more susceptible to fire than concrete shops because casualties in concrete block shops were lesser than that of shanties. Some market authorities had already started handling this situation by building concrete shops all over their markets in Nigeria and this had reduced the cases of fire outbreaks in many markets.

- Poor Electrical Wiring: According to Ozioma (2020) there are some markets you would go into and wonder if the electricians that did the electrical connections were at tug of war. They crisscross wires all over the place and leave some dangling dangerously. Even inside the shops, some electrical connections were nothing to write home about.

- Use of Generators inside the Market: Using generators inside the market doesn't only cause noise and air pollutions, but can also cause fire outbreak or fuel its spread. How this can cause fire outbreak will be understood if someone considers the fact that generators use fuel (petrol), which can easily ignite when it comes in contact with heat.

- Cooking inside the Market: In markets such as Onitsha Main Market, some women kept small kerosene stoves and camping gas cookers in their shops, which they use for cooking or heat up food for their children. This had the potential of causing fires.

- Filling Stations and Gas Plants near Markets: Because of the large number of generators inside the market, business owners had decided to bring filling stations closer to markets. This could not 
even be compared to those that sold fuel in kegs right inside the market, targeting those that couldn't leave their shops and walk over to the filling stations. These were potential sources of fires in markets.

In his study on 'analysis of Causes and Characteristics of Market Fires in Lagos State Nigeria', Ayobami et. al (2016) concluded that most of the fire outbreaks at markets in Lagos State Nigeria have been attributed to power surge and vulnerable building materials. Thus, practical efforts should be taken by the government to put every market in a safe state. This could include the demolishing of every vulnerable and illegal structure in markets and reconstruction to modern and resilient standards after proper and adequate consultations with stakeholder.

Boateng (2013) posited that improper electrical fittings, use of substandard electrical materials, defective generators, power fluctuations resulting from frequent power outages and illegal tapping from the national grid are some of the possible causes of fire outbreak. Anaglatey (2013) says the rise in fire outbreak could be traced to intense harmattan, overloading of electrical appliance on the same fuse and improper electrical installation in homes and workplace. He continues that illegal, improper and old wiring system as well as cooking in the home and workplace with naked fire are some of the major causes of frequent fire outbreaks. Abu (2013) reports that $75 \%$ of fire outbreak in Ghana are caused by smoking, $15 \%$ out of ignorance and $10 \%$ out of accidents.

\section{ENVIRONMENTAL IMPACT OF FIRE ON MARKETS}

Fires can cause devastating effects on the environment. Fires events can cause tangible costs to property and human life in market places. Martin et. al. (2016) proposes that quantification of fire related costs could provide a metric for understanding the social and economic impact of fire, which could be useful for assessing and influencing fire prevention and protection. In addition, fires also inflict adverse consequences on the natural environment around markets. These include contamination of the air via smoke and its subsequent diffusion, with deposition of particulate and other materials likely to contaminate soil and water. Contamination of soil and water from fire suppression runoff might contain hazardous materials that may further lead to pollution. Fires could also cause massive destruction to market infrastructure such as stands, shops, store rooms, restaurants and so on. This could lead to massive losses of property and render business owners desperate. This could affect local economies in the long run. Moreover, market fires can also cause injuries and loss of life. Fires could also destroy the aesthetic beauty of market environments.

\section{Proposed Approaches to Fire Safety Management in Zambian Markets}

Having reviewed literature on fire safety in markets, we propose that the following be done as a holistic approach in order to improve on fire safety in Zambian markets:
(a) Education and training of marketeers and consumers
(b) Installation and maintenance of market fire facilities
(c) Security and surveillance of market environment
(d) Improving quality of market structures
(e) Monitoring and Evaluation

Figure1 Presents a summary of the proposed approaches.

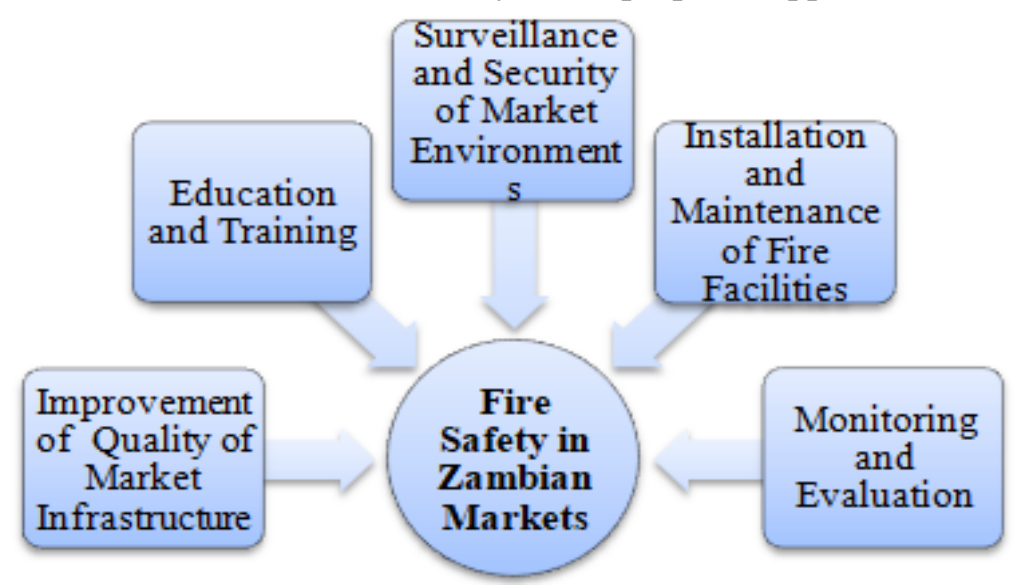

Figure2. Proposed approaches to fire safety management in Zambian markets

Source: Mubita (2020) 


\section{(a) Education and Training of Marketers and Consumers}

One of the key strategies to maintaining a safe market place from fires is through fire safety training and education. With proper training and education, marketeers can eliminate fire hazards and respond quickly and efficiently if a fire broke out. Without proper training and education, a small occurrence of fire could quickly grow to become a major incident with devastating outcomes because marketeers may not know how to go about fire extinction. Fire safety training and education could also teach marketeers how to identify fire hazards, conduct a fire safety risk assessment, conduct fire safety inspection and audit at individual levels and prevent market fires. Education and training in fire safety would also help marketeers know how to respond if a fire occurred. Fire safety training and education teaches sellers and buyers how to prevent fires. If marketeers are aware of the best ways to prevent and control fires, they can contribute significantly to a safer market place. Lack of training and orientation was also noted by Kaiko (2016) as a barrier to effective safety and health management in public places like schools, markets and others. This was because an informed mind has the potential of acting responsibly.

\section{What to teach marketeers and consumers about fire safety in markets}

We propose that marketeers and consumers be taught the following to ensure that market places in Zambia are safe from fire:

- The market management should ensure that people in markets are taught about electrical safety. They should be taught that faulty wiring and malfunctioning electrical equipment can be a source of fire and should therefore be repaired as soon as possible. They should also be taught that electrical repairs should be done only by qualified and authorized personnel.

- Marketeers and consumers should be taught about housekeeping. Housekeeping should be maintained all times in market places. A thoroughly cleaned, well-maintained market environment promotes a feeling of safety, comfort and enjoyment to both marketeers and consumers. The marketeers should be taught that the environment should be kept clean because litter and other material could act as fuel for fire. They should be aware that littered debris may block access to fire emergency exits and firefighting equipment.

- One of the most common causes of market fires is careless smoking. Marketeers and consumers should be taught or encouraged to smoke only in designated areas and extinguish smoking materials safely. They should be taught never to smoke in shops and other places like storerooms or chemical storage areas as this could be a recipe for fire.

- The other way to teach marketeers and consumers about fire safety is by the use of fire safety signage. The market management could put up signage in designated market places to communicate messages of fire safety to both marketeers and consumers.

- People in markets should also be taught about basic fire chemistry. They should be taught how to be aware of possible ignition sources when working in potentially explosive atmospheres, such as those containing flammable liquid vapours or fine particles. They should also be taught how to identify fuel sources and keep them safe so as to avoid fire outbreaks in markets.

- People in markets should also be taught how to properly use firefighting equipment like fire extinguishers, fire buckets and hose reels. They should be taught which extinguishers to use for the specific type of fire.

\section{(b) Installation and Maintenance of Market Fire Facilities}

Installation of fire safety equipment in market places could help to protect both market infrastructure as well as the people in and around it. These could be crucial in an even of fire in markets. All designated areas in markets should have deterrent, detection, warning and firefighting components, such as smoke detectors, fire alarm systems, fire extinguishers, emergency lighting, fire hose reels, fire buckets and other firefighting equipment. Installation of fire fighting equipment in public places was also noted by Kaiko and Namafe (2016) as an ideal way of enhancing fire safety and preparedness. But while having these individual pieces of equipment fitted is a great practice, looking after the safety of firefighting facilities should be an ongoing task which should not just be ignored (Kaiko, M, Timothy K. Phiri, Pauline N. Monde, Steria M. Simooya, 2016). There should be a routine process in place for all firefighting equipment inspection and maintenance. Ongoing maintenance would make sure that the equipment that is in place is ready to address a fire emergency as efficient as 
possible. Without maintenance, equipment could easily fall into disrepair or become broken, and this could be impossible to use in an event of fire.

\section{(c) Security and Surveillance of Market Environments}

Surveillance means constantly watching over something. In the context of this paper, it refers to monitoring or watching over the whole market premises closely. It means that the whole market environment should be closely monitored. Market surveillance entails prevention and investigation of abusive, manipulative or illegal trading practices in the market. Markets surveillance is meant to increased sense of security from intruders who could cause fire deliberately (arsonists). When establishing a surveillance system in markets, market property is protected. Market surveillance also entails prevention and investigation of abusive, manipulative or illegal trading practices in the markets that could cause fire.

A surveillance system of a closed-circuit television system could be installed in markets to maintain close observation of a person or group of intruders who could cause fire. More so, security officers could also be employed to look into the issues of security of markets and arsonists among other things. Another way to improve surveillance of market places is to improve lighting of hidden social spaces, passages, pavements, entrances and exits so as to easily take note of intruders. This could help reduce the chances of fire events in markets due to arsonism.

\section{(d) Improving Quality of Market Structures}

Most market structures as earlier noted are made up of flammable materials. Most market stands, shops and other buildings are made of wood, paper, textile, grass and other flammable materials. These could easily catch fire and help fire spread easily. Ozioma (2020) also noted that in Nigeria, most of the shops that were shanty houses made with woods and metal sheets. Most of the stands and shops, especially in rural markets were of substandard. They were vulnerable to fire, strong winds and heavy rains. Therefore, in order to help reduce cases of fire outbreaks in Zambian markets, there are need to improve the quality of market infrastructure. Market structures in Zambia could be built of steel, concrete and other non-flammable or fire flame resistant materials to reduce on fire outbreaks and destruction in Zambian markets.

\section{(e) Monitoring and Evaluation}

The market management and the local authorities should be involved in monitoring all fire safety management rules and regulations put in place. This could be done through monitoring and evaluation on planned intervals. In market places, the purpose of monitoring and evaluation is to track implementation of fire safety plans and outputs systematically, and measure the effectiveness of fire safety programmes drawn. This could help determine exactly whether the set fire safety measures are on track and when changes may be needed. The monitoring and evaluation of fire safety plans at markets could be done by trained personnel and locals to create a sense of belonging.

\section{CONCLUSION}

From the foregoing proposed approaches to fire safety management in Zambia, it is evident that securing a market place against risk of fire requires a holistic approach. This holistic approach involves integrating all activities related to fire management in markets such as prevention, preparedness, suppression and restoration, into one coordinated process of fire management policy, planning and implementation. Therefore, all basic features of the market environment have to be taken care of in planning and implementation. The people in markets are key to its safety from fire hazards and disasters. Integrating all actors and sectors involved in fire management in markets is fundamental. The people in markets as internal stakeholders should be trained in fire safety education so that they are able to spot or identify fire hazards. As noted in the introduction, fire starts with a combination of three elements: oxygen, fuel and heat. Therefore, marketeers should be educated on hazards associated with these three elements so that fire risks are reduced to as low as reasonably practicable. They should be taught, for example, on how to store flammable liquids like diesel, paraffin, petrol and so on. More so, the quality of market infrastructure should be changed. As noted earlier, in most Zambian markets, infrastructure is made up of flammable materials. This should be changed to concrete, steel and other non-flammable materials. Surveillance of market places is also a crucial act in monitoring intruders who could cause fire in market places through arsonism. 
In relation to the foregoing, it is important to adopt a balanced view of fire safety management in markets for both physical and social spaces. All stakeholders should be involved in planning and implementation of fire safety management in Zambian markets. There is also need for a continuous monitoring and evaluation of fire safety practices in market places.

\section{REFERENCES}

[1] Abu, J. (2013). Smoking is number one cause of fire outbreak in Ghana. Ghana News Agency, Monday 18th March

[2] Addai E, Tulashie S, Annan JYeboah I .(2016). Trend of Fire Outbreaks in Ghana and Ways to Prevent These Incidents. Safety and Health at Work (2016) 7(4) 284-292 DOI: 10.1016/j.shaw.2016.02.004

[3] Anaglatey, P. B. (2013) Accra continues to record fire outbreaks. The Chronicle, Monday, 30th July

[4] Anglatey, P. B. (2013) Ghana National Fire Service records 254 fire outbreaks 14 days in 2013. Daily Graphic, Tuesday, 15th January

[5] Boateng, W. 2013. Electricity Company of Ghana explains causes of fire outbreaks. Ghanaian Times, Thursday, 24th January

[6] Chidakwa, B. (2019).Fire guts Mbare market complex. The Herald

[7] Daniel E. Della-Giustina (2014). Fire Safety Management Handbook. CRC Press; 3rd edition

[8] Elabbani, A. (2015). Basic principles of fire. Retrieved on 11 December, 2019

[9] Furness, A and Muckett, M. (2007). Introduction to fire safety management. Elsevier, London

[10] Hughes, P and Ferrett, E. (2007). Introduction to Health and Safety at Work. Third edition. The handbook for students on NEBOSH and other introductory H\&S courses pages 23-27

[11] Ifeoluwa A. (2020). Lagos Market Fire Wrecks 14 Shops, 16 Kiosks. Premium Times, Nigeria, Lagos

[12] Kaiko, M and Namafe, C.M (2016). Safety and Health Issues at Sefula Secondary School of Western Zambia. International Journal of Humanities Social Sciences and Education (IJHSSE) Volume 3, Issue 9, September 2016, PP 91-99 ISSN 2349-0373

[13] Kaiko, M et. al. (2016). Safety and Health Issues in Selected Schools of Chibombo District in Central Province of Zambia. International Journal of Humanities Social Sciences and Education (IJHSSE) Volume 3, Issue 10, October 2016, PP 99-109 ISSN 2349-0373

[14] Kaiko, M. (2016). Barriers to effective safety and health management at Sefula secondary school in western Zambia. Asian Journal of Management Sciences \& Education Vol. 5(4) October 2016, pp 88-95

[15] Lusaka Times, (January 30, 2009) Fire destroys goods at Chisokone Market

[16] Lusaka Times. (2017). Lusaka City Market is on Fire. Lusaka, Zambia

[17] Martin, D., Tomida, M. \& Meacham, B. Environmental impact of fire. Fire Sci Rev 5, 5 (2016). https://doi.org/10.1186/s40038-016-0014-1

[18] Morris, S. E.; Moses, T. A. (1987). "Forest Fire and the Natural Soil Erosion Regime in the Colorado Front Range". Annals of the Association of American Geographers. 77 (2): 245-54. doi:10.1111/j.14678306.1987.tb00156.x.

[19] Mwale, J.J (2014). K1.2 Billion Worth of Property Lost in Two Market Fires. Malawi News Agency, Lilongwe

[20] National Wildfire Coordinating Group. November 2009. Retrieved 2008-12-18

[21] Ozioma, O.k. (2020). Causes of Fire Outbreaks in Nigerian Markets. Retrieved 2020-10-18

[22] Phiri, C. (2018). Comesa market gutted. Zambia Reports, Lusaka, Zambia

[23] Popoola, A.A, Adekalu, O.B, Audu, A.A, Adeleye, B.M, Jiyah. (2016). Analysis of causes and characteristics of market fires in Lagos state, Nigeria

[24] The Zambian Observer, April 16, (2017). Kamwala market in Lusaka on fire just now. Lusaka, Zambia

[25] Voice of America. (2019). Nigerian Fire-fighters Battle Huge Blaze at Market in Lagos. Associated Press, Lagos Nigeria

[26] World Health Organization. Injuries and Violence: The Facts; World Health Organization: Geneva, Switzerland, 2004.

[27] World Health Organization. Burn Prevention, Success Stories Lessons Learned; World Health Organization: Geneva, Switzerland, 2011.

[28] Zambia Reports,August 30, (2017). Zambia's Masala market on fire. Lusaka, Zambia

[29] Zambia Reports, May 20, (2017). Senanga Market on fire. Lusaka, Zambia 


\section{AUTHORS' BIOGRAPHY}
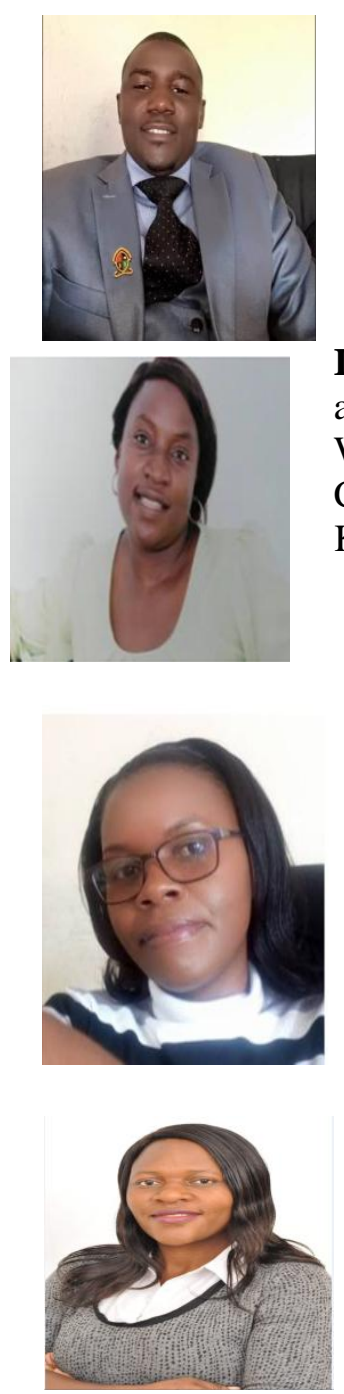

Kaiko Mubita (PhD), is a lecturer and researcher of Geography and Environmental Education at the University of Zambia. His research interests are in Occupational Health and Safety, Environmental Hazards and Disasters and Geography Education.

Inonge Milupi, $\mathbf{D}(\mathbf{P h D})$, is a lecturer and researcher of Environmental Education at the University of Zambia and a Post-Doctoral fellow at the University of Waterloo in Canada. Her research interest includes Environment and Society, Climate Change, Gender, Natural Resource Conservation and Indigenous Knowledge.

Pauline N. Monde is a lecturer and researcher at the University of Zambia in the Department of Language and Social Sciences Education. She is currently enrolled for $\mathrm{PhD}$ in Environmental Education at the same institution. Her areas of research interests include but not limited to Environmental Management, Environmental Governance and Ecological issues.

Steriah M. Simooya, is a lecturer and researcher at the University of Zambia in the Department of Language and Social Sciences Education. Her areas of research interest include but not limited to Environmental Management, Environmental Journalism and Environmental Education.

Citation: Kaiko Mubita, et.al. "A Proposed Holistic Approach to Fire Safety Management in Zambian Markets" International Journal of Humanities Social Sciences and Education (IJHSSE), vol 7, no. 11, 2020, pp. 93-101. doi: https://doi.org/10.20431/2349-0381.0711011.

Copyright: (C) 2020 Authors. This is an open-access article distributed under the terms of the Creative Commons Attribution License, which permits unrestricted use, distribution, and reproduction in any medium, provided the original author and source are credited. 